\title{
Monitoring Patient Respiratory Effort During Mechanical Ventilation: Lung and Diaphragm-Protective Ventilation
}

\author{
Michele Bertoni ${ }^{1}$, Savino Spadaro ${ }^{2}$ and Ewan C. Goligher ${ }^{3,4,5^{*}}$
}

\begin{abstract}
This article is one of ten reviews selected from the Annual Update in Intensive Care and Emergency Medicine 2020. Other selected articles can be found online at https://www.biomedcentral.com/collections/annualupdate2020. Further information about the Annual Update in Intensive Care and Emergency Medicine is available from http://www.springer.com/series/8901.
\end{abstract}

\section{Introduction}

At some point during mechanical ventilation, spontaneous breathing must commence. Spontaneous breathing presents a clinically important risk of injury to the lung and diaphragm. While clinicians are primarily focused on monitoring lung function to prevent ventilatorinduced lung injury (VILI) during passive mechanical ventilation, less attention may be paid to the risk of VILI during assisted mechanical ventilation. Vigorous spontaneous inspiratory effort can cause both lung injury (patient self-inflicted lung injury [P-SILI]) [1, 2] and diaphragm injury (myotrauma) [3, 4]. These injuries lead to prolonged ventilation, difficult weaning, and increased morbidity and mortality [5-7]. Safe spontaneous breathing presents a complex challenge because one must aim to minimize the volume and transpulmonary pressure $\left(P_{\mathrm{L}}\right)$ to avoid P-SILI while also maintaining an appropriate level of patient respiratory effort to avoid diaphragm atrophy. To this end, respiratory monitoring is key. Several practical methods are available for monitoring patient respiratory effort during assisted mechanical ventilation; this review describes their use in clinical practice.

\footnotetext{
* Correspondence: ewan.goligher@utoronto.ca

${ }^{3}$ Interdepartmental Division of Critical Care Medicine, University of Toronto, Toronto, Canada

${ }^{4}$ Division of Respirology, Department of Medicine, University Health Network, Toronto, Canada

Full list of author information is available at the end of the article
}

\section{Mechanics of Spontaneous Breathing}

During assisted mechanical ventilation, each breath results from a negative deflection in pleural pressure $\left(P_{\mathrm{pl}}\right)$ (arising from patient respiratory effort) combined with a positive airway pressure $\left(P_{\text {aw }}\right)$ delivered by the ventilator. The $P_{\text {aw }}$ increases to the support level set on the ventilator, whereas $P_{\mathrm{pl}}$ deflects proportionally to patient effort. $P_{\mathrm{L}}$ corresponds to the difference between $P_{\mathrm{aw}}$ and $P_{\mathrm{pl}}$ $\left(P_{\mathrm{L}}=P_{\mathrm{aw}}-P_{\mathrm{pl}}\right)$; this pressure reflects the stress applied to the lung by the combined effects of ventilator and patient effort. Although in passive mechanical ventilation $P_{\text {aw }}$ is a reasonable surrogate for $P_{\mathrm{L}}$ [8], during assisted mechanical ventilation, vigorous inspiratory efforts can increase the $P_{\mathrm{L}}$ above a "safe limit." Such excessive pressures are "unseen" when relying on the ventilator $P_{\mathrm{aw}}$ waveform; at the same airway pressure value, transpulmonary pressure could be much higher in assisted than in controlled mechanical ventilation (Fig. 1).

\section{Lung Injury During Spontaneous Breathing: Patient Self-Inflicted Lung Injury}

During spontaneous breathing, vigorous patient respiratory efforts can cause lung injury (P-SILI) through different mechanisms (Fig. 2).

- Excessive global lung stress. As already discussed, patient respiratory efforts can increase tidal volume and $P_{\mathrm{L}}$ above safe limits when respiratory drive is elevated. 


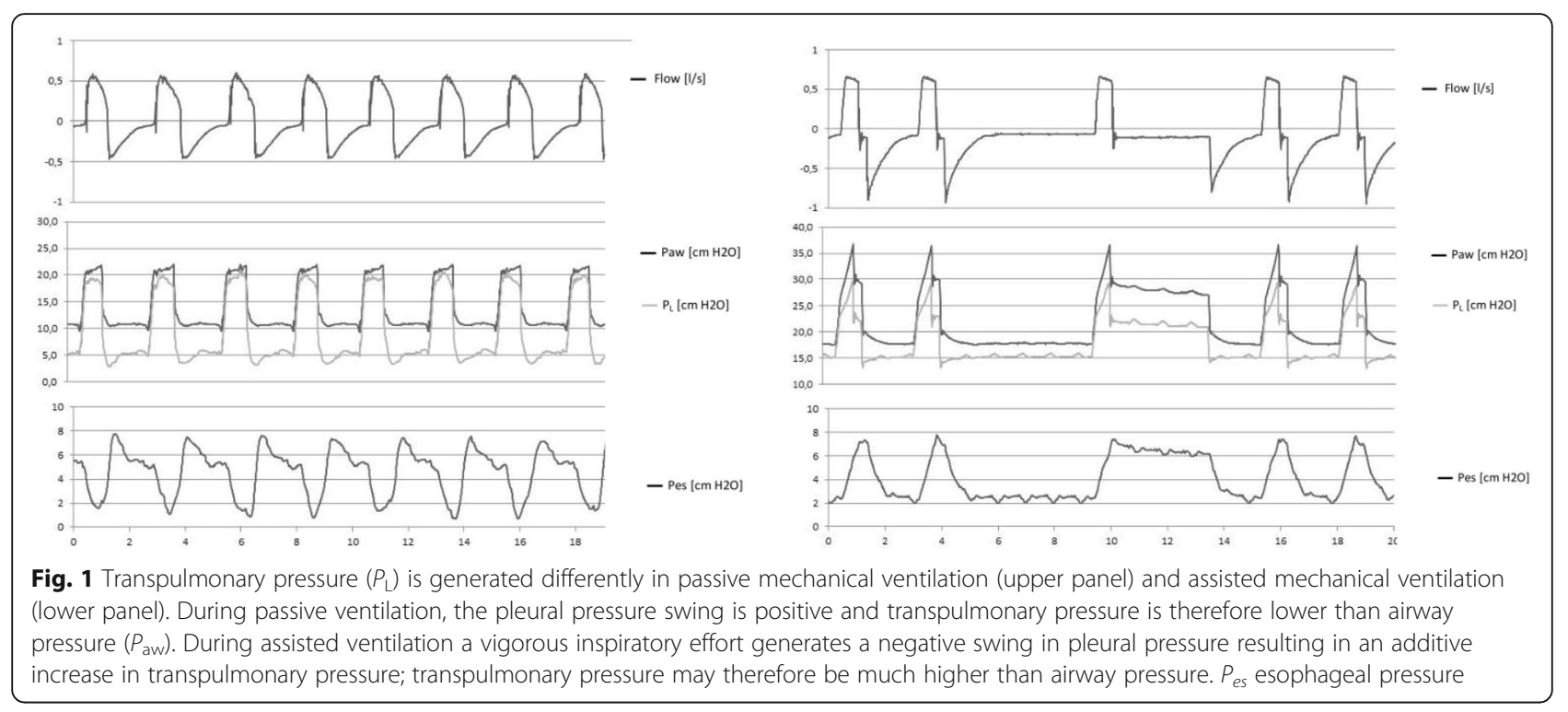

- Excessive regional lung stress. In the injured lung, collapsed and consolidated lung introduces parenchymal mechanical heterogeneities [9], increasing the risk of volutrauma through regional stress amplification. Mechanical stress and strain is not evenly redistributed during inflation.

Consequently, inspiratory efforts generate large $P_{\mathrm{L}}$ swings in dorsal consolidated regions, resulting in the movement of air from nondependent to dependent regions (pendelluft). While this recruits collapsed lung and improves ventilation-perfusion mismatch, this phenomenon increases the overstretch of dependent lung area. In this case, the rise in $P_{\mathrm{L}}$ detected by esophageal manometry may not be a reliable measure of the local stress [10].

- Transvascular pressure and pulmonary edema. During spontaneous breathing, the negative $P_{\mathrm{pl}}$ generated by respiratory effort raises transvascular pressure (the pressure gradient driving fluid migration across pulmonary vessels), increasing total lung water and pulmonary edema $[9,10]$ and further impairing respiratory function.

- Asynchronies. Ventilator asynchronies, including double triggering (double mechanical breaths from a single inspiratory effort) and reverse triggering (diaphragm contractions induced by passive thoracic insufflation in passively ventilated patients) [11] can increase tidal volume and $P_{\mathrm{L}}$ and generate pendelluft, leading to lung injury.

Close monitoring of patient respiratory effort during assisted mechanical ventilation to detect and mitigate these potential injury mechanisms is therefore imperative.

\section{Diaphragm Injury During Spontaneous Breathing: Myotrauma}

The inappropriate use of mechanical ventilation can injure not only the lung (barotrauma and volutrauma) but also respiratory muscles (myotrauma). Mechanical ventilation causes myotrauma by various mechanisms, leading to a final common pathway of VIDD [5].

Mechanisms of myotrauma are summarized in Fig. 2:

- Excessive unloading. Over-assistance from mechanical ventilation and suppression of respiratory drive from sedation leads to acute disuse atrophy and diaphragm weakness [12]. Diaphragmatic unloading caused by over-assisted ventilation (both in control or assisted mode) is frequent during mechanical ventilation, in particular during the first $48 \mathrm{~h}$. Of note, the low level of respiratory effort required to trigger the ventilator is not sufficient to avoid disuse atrophy [3], such that diaphragm atrophy can occur under pressure support ventilation.

- Excessive concentric loading. The diaphragm is sensitive to excessive respiratory load. Higher inspiratory patient effort, dyssynchronies, and under-assistance due to an insufficient level of support are frequent in assisted mechanical ventilation. Vigorous concentric contractions provoke high muscular tension resulting in muscle inflammation, proteolysis, myofibrillar damage, and sarcolemma disarray $[13,14]$. In critically ill patients, systemic inflammation renders muscle myofibrils more vulnerable to mechanical injury $([10,15]$.

- Eccentric loading. Eccentric contractions occur when a muscle generates contractile tension while 


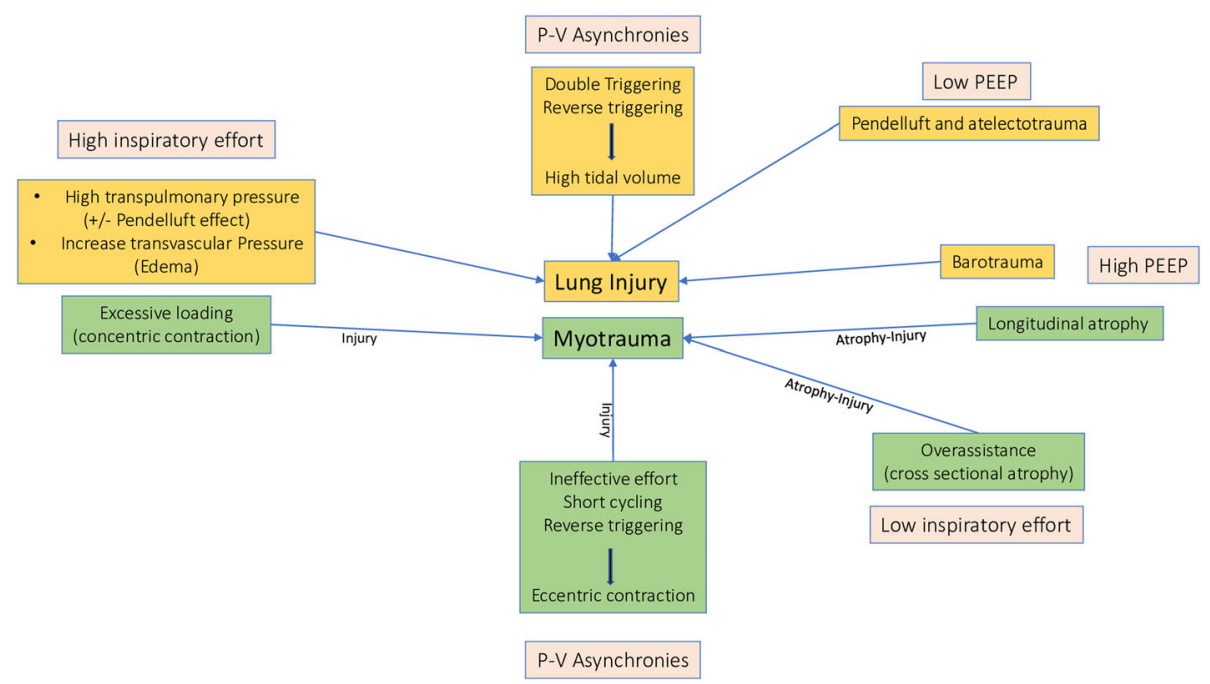

Fig. 2 Mechanisms of lung-diaphragm injury in spontaneous breathing patients under assisted mechanical ventilation. Note that some of these mechanisms also apply under controlled mechanical ventilation (e.g., reverse triggering). PEEP positive end-expiratory pressure

it is lengthening (rather than shortening); such contractions are much more injurious than concentric (shortening) contractions [16]. When a low positive end-expiratory pressure (PEEP) and excessive reduction in end-expiratory lung volume are present, the diaphragm contracts even as it lengthens during the expiratory ("post-inspiratory") phase to avoid atelectasis ("expiratory braking" phenomenon) [17]. Specific forms of dyssynchrony (reverse triggering, short cycling, ineffective effort) can generate eccentric contractions because the diaphragm is activated during the expiratory phase.

- Excessive PEEP. Preliminary experimental evidence suggests that maintaining the diaphragm at a shorter length with the use of excessive PEEP may cause sarcomeres to "drop out" of the muscle and shorten its length (longitudinal atrophy) [18]. This could theoretically disadvantage the length-tension characteristics of the muscle once PEEP is reduced, impairing diaphragm performance.

The first three of these injury mechanisms can be detected by monitoring respiratory effort, emphasizing the potential for such monitoring to help clinicians ensure safe spontaneous breathing during mechanical ventilation. We now proceed to review a range of monitoring techniques to achieve this goal.

\section{Monitoring Spontaneous Breathing Using Esophageal Pressure}

The use of esophageal pressure $\left(P_{\mathrm{es}}\right)$ monitoring is welldescribed in patients with acute respiratory distress syndrome (ARDS) under passive mechanical ventilation
[19]. This technique is also the gold standard to assess respiratory effort and work of breathing but its use remains uncommon, perhaps because the utility of the information derived from $P_{\mathrm{es}}$ has been under-appreciated. When used to monitor the safety of spontaneous breathing, $P_{\text {es }}$ monitoring permits several different relevant quantities to be estimated.

\section{Transpulmonary Pressure}

$P_{\text {es }}$ can be used as a surrogate measure of $P_{\mathrm{p}}$, bearing in mind regional variations [20]. It can therefore be used to measure $P_{\mathrm{L}}\left(P_{\mathrm{aw}}-P_{\mathrm{pl}}\right)$, by substituting $P_{\mathrm{pl}}$ with $P_{\mathrm{es}}$. As shown in Fig. $1, P_{\mathrm{L}}$ can easily reach an injuriously high value during assisted mechanical ventilation (where both patient and ventilator distend the lung). An acceptable upper limit for $P_{\mathrm{L}}$ has not yet been defined; a "precautionary" peak inspiratory value of $20 \mathrm{cmH}_{2} \mathrm{O}$ in a lunginjured patient is a reasonable target to limit the risk of injury $[2,21]$.

Of note, in the presence of regional ventilation heterogeneity and pendelluft, the measured value of $P_{\mathrm{L}}$ will underestimate lung stress in the dependent lung areas. While the quasi-static plateau $P_{\mathrm{L}}$ obtained during an endinspiratory occlusion reflects lung stress during passive ventilation, the dynamic swing in $P_{\mathrm{L}}\left(\Delta P_{\mathrm{L}}\right)$ may perhaps be more reflective of injury risk during spontaneous breathing because of the pendelluft phenomenon [22] $\Delta P_{\mathrm{L}}$ likely reflects the upper limit of mechanical stress experienced in dorsal regions of the lung under dynamic conditions [23]. Moreover, various lines of evidence suggest that the dynamic (tidal increase) in lung stress is a more important driver of lung injury than the global (peak) lung stress [24-26]. 


\section{Respiratory Muscle Pressure}

$P_{\text {es }}$ permits measurement of inspiratory effort. The inspiratory muscle pressure $\left(P_{\text {mus }}\right)$ corresponds to the global force generated by the inspiratory muscles. Although the diaphragm is the most important respiratory muscle, accessory inspiratory muscles (rib cage, sternomastoid, and scalene muscles) contribute significantly during vigorous effort, especially when diaphragm function is impaired. As shown in Fig. 3, $P_{\text {mus }}$ is computed from the difference between $P_{\mathrm{es}}$ and the additional pressure required to overcome the chest wall elastic recoil $\left(P_{\mathrm{cw}}\right)$ $\left(P_{\text {mus }}=P_{\mathrm{cw}}-P_{\mathrm{es}}\right)$.

Optimal levels of $P_{\text {mus }}$ during assisted mechanical ventilation are uncertain; recent data suggest that $P_{\text {mus }}$ values similar to those of healthy subjects breathing at rest may be safe and may prevent diaphragm atrophy $\left(5-10 \mathrm{cmH}_{2} \mathrm{O}\right)$ [4, 27]. In routine clinical practice, one can generally disregard the correction for $P_{\mathrm{cw}}$ because chest wall elastance is usually relatively low (even when pleural pressures are elevated). Hence, a target $\Delta P_{\text {es }}$ of around 3-8 $\mathrm{cmH}_{2} \mathrm{O}$ can be considered reasonably comparable to a normal $P_{\text {mus }}$ of $5-10 \mathrm{cmH}_{2} \mathrm{O}$.

The gold standard measurement of respiratory effort is the integral of $P_{\text {mus }}$ over the duration of inspiration (pressure-time product [PTP]) (Fig. 3). PTP is closely correlated to inspiratory muscle energy expenditure. PTP values between 50 and $100 \mathrm{cmH}_{2} \mathrm{O} / \mathrm{s} / \mathrm{min}$ probably reflect appropriate oxygen consumption and acceptable respiratory effort [28].

In routine clinical practice, the magnitude and frequency of the swing in $\Delta P_{\mathrm{es}}$ are probably sufficient to monitor respiratory effort.

\section{Transdiaphragmatic Pressure}

A double balloon catheter can be used to monitor inspiratory swings in $P_{\text {es }}$ and gastric pressure $\left(P_{\text {ga }}\right)$ to specifically quantify the pressure generated by the diaphragm (transdiaphragmatic pressure $\left.\left[P_{\mathrm{di}}\right]\right)$. During an inspiratory effort (depending on the pattern of thoracoabdominal motion), the diaphragm's contractile effort moves the abdominal organs downwards, increasing abdominal pressure (positive swing in $P_{\text {ga }}$ ) and expanding thoracic cavity (negative swing in $P_{\mathrm{es}}$ ). Even when thoracoabdominal motion is such that the diaphragm moves upward during inspiration (i.e., $P_{\text {ga }}$ decreases), the contractile effort of the diaphragm is reflected by the fact that $P_{\mathrm{ga}}$ declines less than $P_{\mathrm{es}}$ (and thus $P_{\mathrm{di}}$ increases). This technique is used mainly in research rather than clinical practice.

\section{Monitoring Spontaneous Breathing by Occlusion Maneuvers}

Expiratory and inspiratory occlusions represent easy, noninvasive, and reasonably reliable maneuvers to

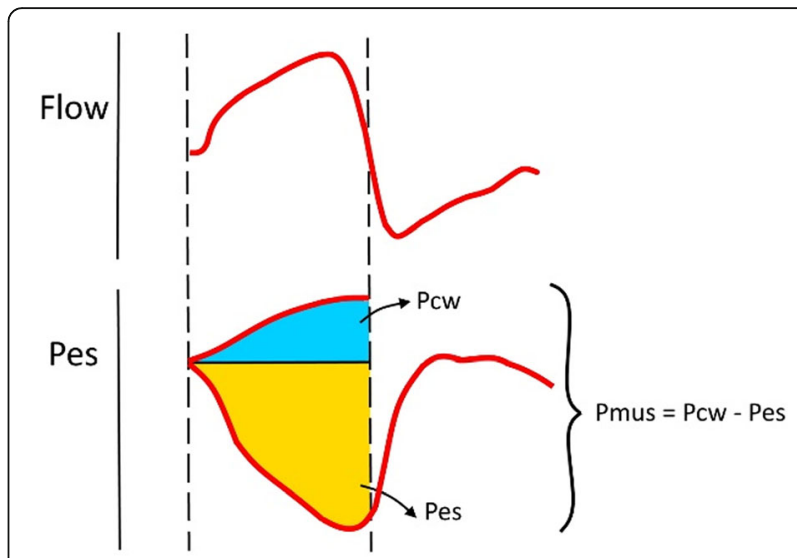

Fig. 3 Computing inspiratory muscle pressure $\left(P_{\text {mus }}\right)$ from the esophageal pressure $\left(P_{\mathrm{es}}\right)$ swing. $P_{\text {mus }}$ derives from the difference between $P_{\text {es }}$ and the added muscle pressure generated to overcome the chest wall elastic recoil $\left(P_{\mathrm{cw}}\right) \cdot P_{\mathrm{cw}}$ represents the elastic recoil of relaxed chest wall; it can be computed as the product of tidal volume and chest wall elastance $\left(E_{\mathrm{cw}}\right)$. The $P_{\text {mus }}$ area over time constitutes the pressure-time product (PTP) (yellow and blue area together)

evaluate the safety of spontaneous breathing in assisted mechanical ventilation.

\section{Inspiratory Occlusion Maneuver}

Brief end-inspiratory occlusion maneuvers are widely used to measure plateau pressure $\left(P_{\text {plat }}\right)$ in passive mechanical ventilation. Driving pressure $(\Delta P)$, calculated as the difference between PEEP and $P_{\mathrm{p}}$, reflects dynamic lung stress and lung injury risk and closely correlates to mortality in patients with ARDS [25]. Bellani et al. [29] suggested that a brief inspiratory occlusion maneuver can enable reliable measurements of $P_{\text {plat }}$ even in assisted mechanical ventilation. During an inspiratory occlusion in assisted mechanical ventilation, patients relax the contracting inspiratory muscles at endinspiration, resulting in an increase in $\Delta P_{\mathrm{aw}}$, easily detectable on the ventilator waveform. When the patient is over-assisted and respiratory effort is low, $P_{\text {aw }}$ drops during the occlusion (Fig. 4). A high $P_{\text {plat }}$ and $\Delta \mathrm{P}$ measured in this way raises concern for hyperdistention and lung injury. Bellani and colleagues [29] recently reported that $\Delta P$ and compliance measured by end-inspiratory occlusion maneuvers during assisted mechanical ventilation predict mortality, supporting the validity and relevance of these measures.

The measurement technique has some limitations. First, because the pressure is obtained under quasi-static conditions this measurement may underestimate the risk of regional lung injury due to the pendelluft mechanism of P-SILI [23]. Second, clinicians need to carefully evaluate the stability and pattern of the $P_{\mathrm{aw}}$ tracing during the occlusion to determine whether the measurement is 
confounded by the action of the abdominal muscles which may rapidly increase $P_{\mathrm{aw}}$ at the onset of neural expiration during the occlusion.

\section{Expiratory Occlusion Maneuver}

Expiratory occlusions are ordinarily employed to measure intrinsic PEEP in passively ventilated patients or to measure maximal inspiratory pressure in spontaneously breathing patients during maximal volitional inspiratory efforts. However, the airway pressure swing during a brief, randomly applied end-expiratory occlusion maneuver (duration equal to one respiratory cycle) may actually be used to assess inspiratory effort. Under occluded conditions, the swing in airway pressure is exactly correlated to the swing in pleural pressure. Consequently, the airway pressure swing during the occlusion $\left(\Delta P_{\text {occ }}\right)$ can be used to assess the presence and magnitude of pleural pressure swings due to patient respiratory effort (taking into account differences in pleural pressure swing between occluded and dynamic conditions). On this basis, $\Delta P_{\text {occ }}$ can be used to predict $\Delta P_{\mathrm{es}}, P_{\text {mus }}$, and $\Delta P_{\mathrm{L}}$ during the respiratory cycle so long as the patient's respiratory drive during the tidal breath is unchanged by a single, brief, and unexpected end-expiratory occlusion [30, 31]. A transient end-expiratory occlusion maneuver is a practical and noninvasive method to routinely detect insufficient or excessive respiratory effort and $P_{\mathrm{L}}$ during assisted mechanical ventilation $[32,33]$.

\section{Airway Occlusion Pressure}

The $P_{0.1}$ (airway pressure generated in the first $100 \mathrm{~ms}$ of inspiration against an expiratory occlusion) provides a measure of the patient's respiratory drive (Fig. 5) [34]. Whitelaw et al. [35] demonstrated that an occlusion does not modify cortical respiratory output until it is prolonged beyond $200 \mathrm{~ms}$. Additionally, during the first $100 \mathrm{~ms}$, respiratory pressure generation is independent of pulmonary mechanics or diaphragm function $[35,36]$. Although the reliability of $P_{0.1}$ has been confirmed only in small studies, a value between 1.5 and $3.5 \mathrm{cmH}_{2} \mathrm{O}$ $[37,38]$ seems to be an easy method to guide clinicians to adjust ventilation during assisted mechanical ventilation [34, 39-41]. $P_{0.1}$ values less than $1.5 \mathrm{cmH}_{2} \mathrm{O}$ might suggest that respiratory effort is inadequate [42], and values greater than $3.5 \mathrm{cmH}_{2} \mathrm{O}$ suggest high respiratory drive [37].

$P_{0.1}$ has several advantages: it is easy and practical to obtain, and most modern ventilators have a function for measuring it. A method for setting the pressure support level based on the $P_{0.1}$ value has been described [43]. $P_{0.1}$ may have substantial intra-patient variability and several repeated measurements are required to estimate a stable mean value. Moreover, in hyperinflated patients, the intrinsic PEEP causes a delay in the fall in $P_{\text {aw }}$, which might give rise to underestimation of $P_{0.1}$. Conti et al. demonstrated that in this condition, commencing the $100 \mathrm{~ms}$ for the $P_{0.1}$
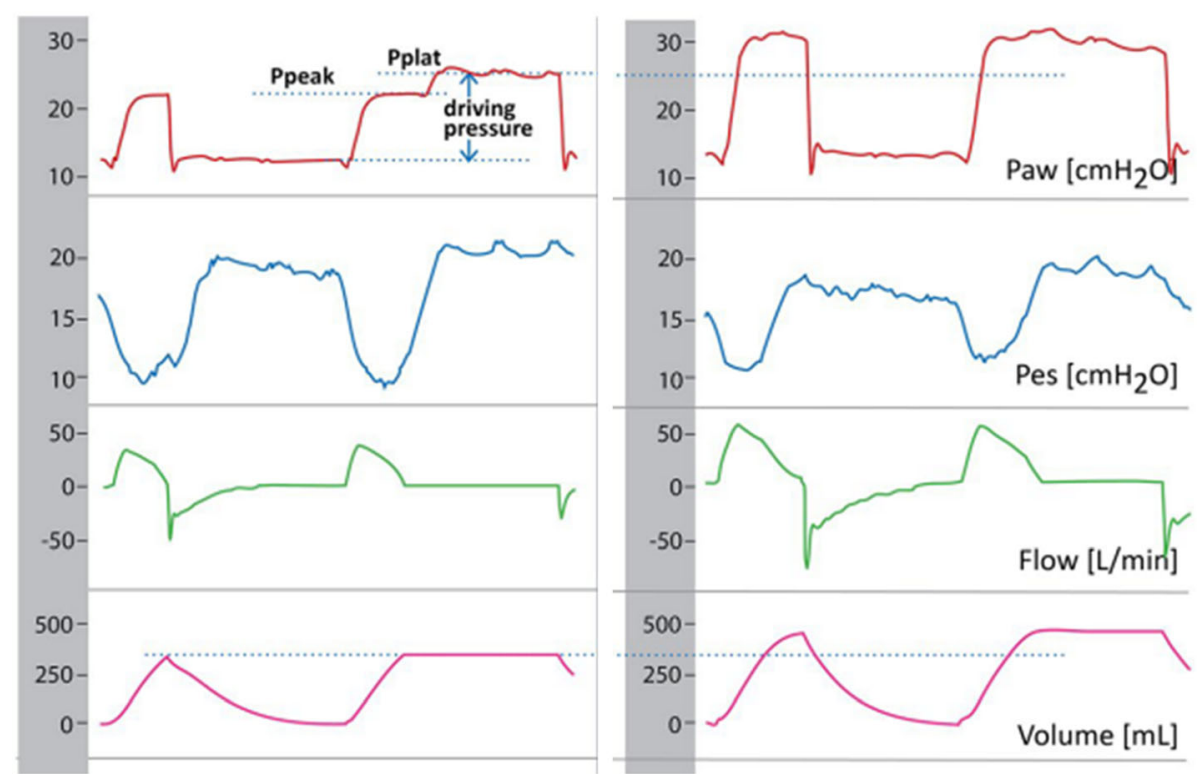

Fig. 4 Measuring plateau pressure $\left(P_{\text {plat }}\right)$ during assisted mechanical ventilation (AMV). A brief inspiratory hold permits a reliable measure of $P_{\text {plat }}$ in AMV, provided the patient relaxes with no immediate expiratory efforts. The difference between $P_{\text {plat }}$ and positive end-expiratory pressure (PEEP) results in the driving pressure $\Delta P_{\text {aw }}$. In panel (a), the patient's inspiratory effort is vigorous (greater esophageal swing): during inspiratory hold, the airflow stops and $P_{\text {plat }}$ rises above $P_{\text {peaki }}$ the previous activated respiratory muscles relaxes and expires, causing $P_{\text {aw }}$ to increase. In panel (b), the patient's inspiratory effort is low: the difference between $P_{\text {peak }}$ and $P_{\text {plat }}$ is minimal, indicating minimal respiratory muscle effort during the current breath. This technique enables respiratory muscle activity to be assessed by measuring $P_{\text {plat. }}$ (Modified from [29] with permission) 
measure when expiratory flow is equal to zero overcomes this problem [44].

\section{Monitoring Spontaneous Breathing by Diaphragm Electrical Activity}

The use of a dedicated catheter fitted with electromyography electrodes permits continuous monitoring of the electrical activity of the diaphragm $\left(\mathrm{EA}_{\mathrm{di}}\right)$ [45]. $\mathrm{EA}_{\mathrm{di}}$ has been demonstrated to be comparable to the transdiaphragmatic pressure, and is more practical than surface electromyography (EMG) [46].

When ventilation is driven by $\mathrm{EA}_{\mathrm{di}}$ (during neurally adjusted ventilatory assist [NAVA]), patient-ventilator interaction improves $[47,48]$; $\mathrm{EA}_{\mathrm{di}}$ also helps clinicians to recognize different asynchronies $[47,49]$. As demonstrated by Barwing et al. [50], the $\mathrm{EA}_{\mathrm{di}}$ trend can be used to detect weaning failure at an early stage [51, 52]: it progressively increases in patients who ultimately fail their spontaneous breathing trial whereas diaphragm activity remains stable in patients who pass the trial. $\mathrm{EA}_{\mathrm{di}}$ alterations appeared before signs of fatigue [50].

As an electrical signal, $\mathrm{EA}_{\mathrm{di}}$ is an expression of respiratory motor output (the central nervous system activation of the diaphragm) and not of diaphragmatic force generation (effort). During resting breathing in healthy subjects, $\mathrm{EA}_{\mathrm{di}}$ varies anywhere between 5 and $30 \mu \mathrm{V}$ [53]. Because of this wide variation, it is difficult to specify a target $\mathrm{EA}_{\mathrm{di}}$ to achieve during mechanical ventilation.
Alternatively, $\mathrm{EA}_{\mathrm{di}}$ can be used to estimate $P_{\text {mus }}$ under different conditions of ventilator assistance [54]. By considering coupling between electrical activity and pressure generation constant during the time (neuro-mechanical coupling $=P_{\text {mus }} / \mathrm{EA}_{\mathrm{di}}$ obtained during expiratory occlusion), $\mathrm{EA}_{\mathrm{di}}$ could permit a breath-by-breath assessment of $P_{\text {mus }}$ during the normal breathing cycle.

\section{Monitoring Spontaneous Breathing by Diaphragm Ultrasound}

The diaphragm ultrasound technique is noninvasive, easy to perform, and reproducible. Variation in diaphragm thickness during the respiratory cycle (thickening fraction, $\mathrm{TF}_{\mathrm{di}}$ ) is correlated to respiratory pressure generation and $\mathrm{EA}_{\mathrm{di}}$ [55] and can be used to detect diaphragm weakness [55]. $\mathrm{TF}_{\mathrm{di}}$ values less than $30 \%$ during a maximal inspiratory effort detect diaphragm weakness with a high sensitivity [55]. Daily measurement of end-expiratory diaphragm thickness can detect structural changes in the respiratory muscles. In mechanically ventilated patients, a progressive increase in diaphragm thickness over time was correlated to excessive effort and may represent under-assistance myotrauma [3]. $\mathrm{TF}_{\mathrm{di}}$ of $15-30 \%$ during tidal ventilation was associated with stable diaphragm thickness and the shortest duration of ventilation [4]. Ultrasound is best used for intermittent patient assessments, as it is not well suited for continuous monitoring.
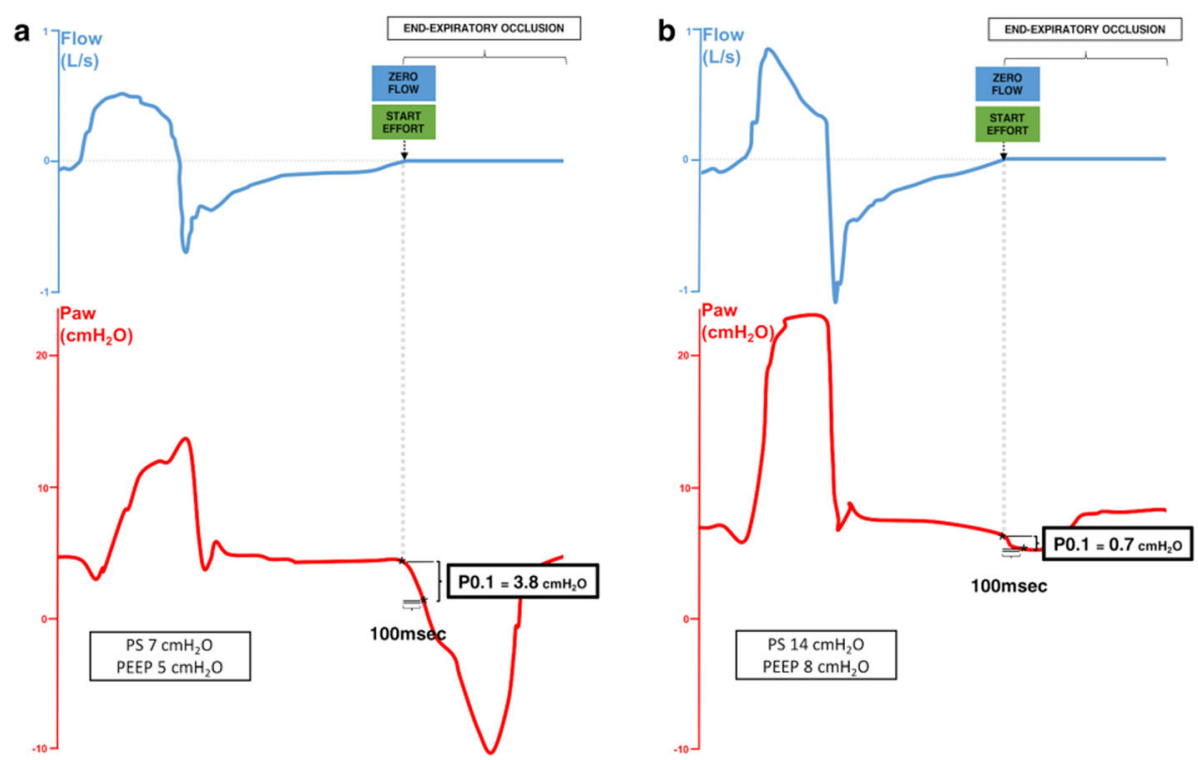

Fig. 5 Airway occlusion pressure $\left(P_{0.1}\right)$ is the airway pressure $\left(P_{\text {aw }}\right)$ generated in the first $100 \mathrm{~ms}$ of inspiration against an expiratory occlusion. Importantly, the $100 \mathrm{~ms}$ time for $P_{0.1}$ calculation should start at the point where the expiratory flow trace reaches zero (dashed line) to correct for potential intrinsic positive end-expiratory pressure (PEEP). PS pressure support level. (From [34] with permission) 
Table 1 Potential target values for safe spontaneous breathing

\begin{tabular}{lll}
\hline Technique & Parameter & Possible target range of values for safe spontaneous breathing \\
\hline Esophageal pressure & Peak end-inspiratory transpulmonary pressure $\left(P_{\mathrm{L}}\right)$ & $\leq 20 \mathrm{cmH}_{2} \mathrm{O}$ \\
& Swing in transpulmonary pressure $\left(\Delta P_{\mathrm{L}}\right)$ & $\leq 15 \mathrm{cmH}_{2} \mathrm{O}$ \\
& Peak inspiratory muscle pressure $\left(P_{\text {mus }}\right)$ & $5-10 \mathrm{cmH}_{2} \mathrm{O}$ \\
& Esophageal pressure swing $\left(\Delta P_{\mathrm{es}}\right)$ & $3-8 \mathrm{cmH}_{2} \mathrm{O}$ \\
& Transdiaphragmatic pressure swing $\left(\Delta P_{\text {di }}\right)$ & $5-10 \mathrm{cmH}_{2} \mathrm{O}$ \\
& Pressure time product (PTP) & $50-100 \mathrm{cmH}_{2} \mathrm{O} / \mathrm{s} / \mathrm{min}$ \\
Occlusion maneuvers & Inspiratory occlusion for plateau airway pressure $\left(P_{\text {plat }}\right)$ & $\leq 30 \mathrm{cmH}_{2} \mathrm{O}$ \\
& Inspiratory occlusion for driving pressure $\left(\Delta P_{\text {aw }}=P_{\text {plat }}-\mathrm{PEEP}\right)$ & $\leq 15 \mathrm{cmH}_{2} \mathrm{O}$ \\
& Expiratory occlusion for estimated $P_{\text {mus }}$ & $5-10 \mathrm{cmH}_{2} \mathrm{O}$ \\
Electromyography & Airway occlusion pressure $\left(P_{0.1}\right)$ & $1.5-3.5 \mathrm{cmH}_{2} \mathrm{O}$ \\
\hline
\end{tabular}

PEEP positive end-expiratory pressure

\section{Conclusion}

Targets for Lung and Diaphragm-Protective Ventilation

Table 1 summarizes the different methods available to monitor inspiratory effort and respiratory drive in assisted mechanical ventilation, along with possible targets for safe spontaneous breathing as discussed throughout this chapter. The interpretation and application of measurements must always be guided by the clinical context. Different forms and phases of acute respiratory failure require somewhat different priorities: in early ARDS, close attention must be taken to avoid high inspiratory effort to limit VILI and P-SILI. Adjustments to ventilation and sedation to obtain a low level of inspiratory effort should be implemented as early as possible to avoid myotrauma.

It remains uncertain whether it is possible to achieve an acceptable level of respiratory effort during the acute phase of illness and this remains a key area for clinical investigation. For the present, clinicians should strive to be aware of patient respiratory effort and appreciate the potential benefits and harms of manipulating respiratory effort during acute respiratory failure.

\section{Acknowledgements}

Not applicable.

\section{Authors' contributions}

$M B$ and EG conceived the work. MB drafted the manuscript, and EG and SS critically revised the manuscript for intellectually important content. All authors read and approved the final manuscript.

\section{Funding}

Publication costs were supported by a Scholarship from the Interdepartmental Division of Critical Care Medicine, University of Toronto. Dr. Goligher is supported by an Early Career Investigator Award from the Canadian Institutes of Health Research

\section{Availability of data and materials}

All data generated or analysed during this study are included in this published article.
Ethics approval and consent to participate

Not applicable.

\section{Consent for publication}

Not applicable.

\section{Competing interests}

The authors declare that they have no competing interests.

\section{Author details}

${ }^{1}$ Department of Anesthesia, Critical Care and Emergency, Spedali Civili University Hospital, Brescia, Italy. ${ }^{2}$ Department of Morphology, Surgery and Experimental Medicine, Intensive Care Unit, University of Ferrara, Sant'Anna Hospital, Ferrara, Italy. ${ }^{3}$ Interdepartmental Division of Critical Care Medicine, University of Toronto, Toronto, Canada. ${ }^{4}$ Division of Respirology, Department of Medicine, University Health Network, Toronto, Canada. ${ }^{5}$ Toronto General Hospital Research Institute, Toronto, Canada.

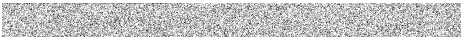

\section{References}

1. Yoshida T, Uchiyama A, Matsuura N, et al. Spontaneous breathing during lung-protective ventilation in an experimental acute lung injury model: high transpulmonary pressure associated with strong spontaneous breathing effort may worsen lung injury. Crit Care Med. 2012;40:1578-85.

2. Yoshida T, Torsani $V$, Gomes $S$, et al. Spontaneous effort causes occult pendelluft during mechanical ventilation. Am J Respir Crit Care Med. 2013; 188:1420-7.

3. Goligher EC, Fan E, Herridge MS, et al. Evolution of diaphragm thickness during mechanical ventilation: impact of inspiratory effort. Am J Respir Crit Care Med. 2015;192:1080-8.

4. Goligher EC, Dres M, Fan E, et al. Mechanical ventilation-induced diaphragm atrophy strongly impacts clinical outcomes. Am J Respir Crit Care Med. 2018;197:204-13.

5. Goligher EC, Brochard LJ, Reid WD, et al. Diaphragmatic myotrauma: a mediator of prolonged ventilation and poor patient outcomes in acute respiratory failure. Lancet Respir Med. 2019;7:90-8.

6. Dres M, Dubé BP, Mayaux J, et al. Coexistence and impact of limb muscle and diaphragm weakness at time of liberation from mechanical ventilation in medical intensive care unit patients. Am J Respir Crit Care Med. 2017;195: 57-66.

7. Brochard L, Slutsky A, Pesenti A. Mechanical ventilation to minimize progression of lung injury in acute respiratory failure. Am J Respir Crit Care Med. 2017;195:438-42.

8. Chiu L-C, Hu HC, Hung CY, et al. Dynamic driving pressure associated mortality in acute respiratory distress syndrome with extracorporeal membrane oxygenation. Ann Intensive Care. 2017;7:12. 
9. Yoshida T, Fujino Y, Amato MBP, et al. Fifty years of research in ards. Spontaneous breathing during mechanical ventilation. Risks, mechanisms, and management. Am J Respir Crit Care Med. 2017;195:985-92.

10. Yoshida T, Roldan R, Beraldo MA, et al. Spontaneous effort during mechanical ventilation: maximal injury with less positive end-expiratory pressure. Crit Care Med. 2016:44:e678-88.

11. Akoumianaki E, Lyazidi A, Rey $N$, et al. Mechanical ventilation-induced reverse-triggered breaths a frequently unrecognized form of neuromechanical coupling. Chest. 2013;143:927-38.

12. Jung B, Moury PH, Mahul M, et al. Diaphragmatic dysfunction in patients with ICU-acquired weakness and its impact on extubation failure. Intensive Care Med. 2016;42:853-61.

13. Orozco-Levi M, Lloreta J, Minguella J, et al. Injury of the human diaphragm associated with exertion and chronic obstructive pulmonary disease. Am J Respir Crit Care Med. 2001;164:1734-9.

14. Jiang TX, Reid WD, Belcastro A, et al. Load dependence of secondary diaphragm inflammation and injury after acute inspiratory loading. Am J Respir Crit Care Med. 1998;157:230-6.

15. Lin MC, Ebihara S, Dwairi QEL, et al. Diaphragm sarcolemmal injury is induced by sepsis and alleviated by nitric oxide synthase inhibition. Am J Respir Crit Care Med. 1998;158:1656-63.

16. Proske U, Morgan DL. Muscle damage from eccentric exercise: mechanism, mechanical signs, adaptation and clinical applications. J Physiol. 2001;537: 333-45.

17. Pellegrini $\mathrm{M}$, Hedenstierna $\mathrm{G}$, Roneus $\mathrm{A}$, et al. The diaphragm acts as a brake during expiration to prevent lung collapse. Am J Respir Crit Care Med. 2017; 195:1608-16.

18. Lindqvist J, van den Berg M, van der Pijl R, et al. Positive end-expiratory pressure ventilation induces longitudinal atrophy in diaphragm fibers. Am J Respir Crit Care Med. 2018;198:472-85.

19. Fish E, Novack V, Banner-Goodspeed VM, et al. The esophageal pressureguided ventilation 2 (EPVent2) trial protocol: a multicentre, randomised clinical trial of mechanical ventilation guided by transpulmonary pressure. BMJ Open. 2014;4:e006356.

20. Luca Grieco D, Chen L, Brochard L. Transpulmonary pressure: importance and limits. Ann Transl Med. 2017;5:285.

21. Baedorf Kassis E, Loring SH, Talmor D. Mortality and pulmonary mechanics in relation to respiratory system and transpulmonary driving pressures in ARDS. Intensive Care Med. 2016;42:1206-13.

22. Yoshida T, Amato MBP, Grieco DL, et al. Esophageal manometry and regional transpulmonary pressure in lung injury. Am J Respir Crit Care Med. 2018;197:1018-26.

23. Yoshida T, Amato MBP, Kavanagh BP. Understanding spontaneous vs. ventilator breaths: impact and monitoring. Intensive Care Med. 2018;44:2235-8.

24. Protti A, Andreis DT, Monti M, et al. Lung stress and strain during mechanical ventilation: any difference between statics and dynamics? Crit Care Med. 2013;41:1046-55.

25. Amato MBP, Meade MO, Slutsky AS, et al. Driving pressure and survival in the acute respiratory distress syndrome. N Engl J Med. 2015;372:747-55.

26. Chiumello D, Carlesso E, Cadringher $P$, et al. Lung stress and strain during mechanical ventilation for acute respiratory distress syndrome. Am J Respir Crit Care Med. 2008;178:346-55.

27. Carteaux G, Mancebo J, Mercat A, et al. Bedside adjustment of proportional assist ventilation to target a predefined range of respiratory effort. Crit Care Med. 2013;41:2125-32.

28. Mauri T, Yoshida T, Bellani G, et al. Esophageal and transpulmonary pressure in the clinical setting: meaning, usefulness and perspectives. Intensive Care Med. 2016;42:1360-73.

29. Bellani G, Grassi A, Sosio S, et al. Plateau and driving pressure in the presence of spontaneous breathing. Intensive Care Med. 2019;45:97-8.

30. Goldman MD, Grassino A, Mead J, et al. Mechanics of the human diaphragm during voluntary contraction: dynamics. J Appl Physiol. 1978;44:840-8.

31. Grassino A, Goldman MD, Mead J, et al. Mechanics of the human diaphragm during voluntary contraction: statics. J Appl Physiol. 1978;44: 829-39.

32. Spadaro S, Marangoni E, Ragazzi R, et al. A methodological approach for determination of maximal inspiratory pressure in patients undergoing invasive mechanical ventilation. Minerva Anestesiol. 2015;81:33-8.

33. Bertoni $M$, Telias I, Urner $M$, et al. A novel non-invasive method to detect excessively high respiratory effort and dynamic transpulmonary driving pressure during mechanical ventilation. Crit Care. 2019;23:346.
34. Telias I, Damiani F, Brochard L. The airway occlusion pressure (P0.1) to monitor respiratory drive during mechanical ventilation: increasing awareness of a not-so-new problem. Intensive Care Med. 2018:44:1532-5.

35. Whitelaw WA, Derenne JP, Milic-Emili J. Occlusion pressure as a measure of respiratory center output in conscious man. Respir Physiol. 1975;23:181-99.

36. Holle RH, Schoene RB, Pavlin EJ. Effect of respiratory muscle weakness on P0.1 induced by partial curarization. J Appl Physiol. 1984;57:1150-7.

37. Rittayamai N, Beloncle F, Goligher EC, et al. Effect of inspiratory synchronization during pressure-controlled ventilation on lung distension and inspiratory effort. Ann Intensive Care. 2017;7:100.

38. Vargas F, Boyer A, Bui HN, et al. Respiratory failure in chronic obstructive pulmonary disease after extubation: value of expiratory flow limitation and airway occlusion pressure after 0.1 second (P0.1). J Crit Care. 2008;23:577-84

39. Kera T, Aihara A, Inomata T. Reliability of airway occlusion pressure as an index of respiratory motor output. Respir Care. 2013:58:845-9.

40. Alberti A, Gallo F, Fongaro A, et al. P0.1 is a useful parameter in setting the level of pressure support ventilation. Intensive Care Med. 1995;21:547-53.

41. Mauri T, Grasselli G, Suriano G, et al. Control of respiratory drive and effort in extracorporeal membrane oxygenation patients recovering from severe acute respiratory distress syndrome. Anesthesiology. 2016;125:159-67.

42. Pletsch-Assuncao R, Caleffi Pereira M, Ferreira JG, et al. Accuracy of invasive and noninvasive parameters for diagnosing ventilatory overassistance during pressure support ventilation. Crit Care Med. 2018;46:411-7.

43. Iotti GA, Brunner JX, Braschi A, et al. Closed-loop control of airway occlusion pressure at 0.1 second (P0.1) applied to pressure-support ventilation: algorithm and application in intubated patients. Crit Care Med. 1996;24:771-9.

44. Conti G, Cinnella G, Barboni E, et al. Estimation of occlusion pressure during assisted ventilation in patients with intrinsic PEEP. Am J Respir Crit Care Med. 1996;154:907-12.

45. Sinderby C, Navalesi P, Beck J, et al. Neural control of mechanical ventilation in respiratory failure. Nat Med. 1999;5:1433-6.

46. Kim MJ, Druz WS, Danon J, et al. Effects of lung volume and electrode position on the esophageal diaphragmatic EMG. J Appl Physiol. 1978;45: 392-8.

47. Beloncle F, Piquilloud L, Rittayamai N, et al. A diaphragmatic electrical activity-based optimization strategy during pressure support ventilation improves synchronization but does not impact work of breathing. Crit Care. 2017;21:21.

48. Sinderby C, Liu S, Colombo D, et al. An automated and standardized neural index to quantify patient-ventilator interaction. Crit Care. 2013;17:R239.

49. Di Mussi R, Spadaro S, Mirabella L, et al. Impact of prolonged assisted ventilation on diaphragmatic efficiency: NAVA versus PSV. Crit Care. 2016;20:1.

50. Barwing J, Pedroni C, Olgemöller U, et al. Electrical activity of the diaphragm (EAdi) as a monitoring parameter in difficult weaning from respirator: a pilot study. Crit Care. 2013;17:R182.

51. Gross D, Grassino A, Ross WR, et al. Electromyogram pattern of diaphragmatic fatigue. J Appl Physiol. 1979;46:1-7.

52. Dres $M$, Schmidt $M$, Ferre A, et al. Diaphragm electromyographic activity as a predictor of weaning failure. Intensive Care Med. 2012;38:2017-25.

53. Piquilloud L, Beloncle F, Richard JC, Mancebo J, Mercat A, Brochard L. Information conveyed by electrical diaphragmatic activity during unstressed, stressed and assisted spontaneous breathing: a physiological study [Internet]. Ann Intensive Care. 2019;9:89.

54. Bellani G, Mauri T, Coppadoro A, et al. Estimation of patient's inspiratory effort from the electrical activity of the diaphragm. Crit Care Med. 2013;41:1483-91.

55. Goligher EC, Laghi F, Detsky ME, et al. Measuring diaphragm thickness with ultrasound in mechanically ventilated patients: feasibility, reproducibility and validity. Intensive Care Med. 2015;41:642-9.

\section{Publisher's Note}

Springer Nature remains neutral with regard to jurisdictional claims in published maps and institutional affiliations. 